\title{
Social Influence and Customer Referral Value
}

\author{
By Evangelos Xevelonakis*
}

Social media, big data and social influence are currently on everyone's lips. But how do they affect customer value? Satisfied customers represent a major source of customer acquisition in many industries. Suppliers can reduce acquisition costs substantially by using "sales activities" of existing clients. However, if customers are dissatisfied, considerable loss of market share may result from negative word-ofmouth referrals. Social network analysis provides the basics to describe these networks, but how can we quantify customer referral value? In this contribution, we propose a method of determining the social influence of existing customers and of quantifying the economic value derived. Subsequently, we suggest a portfolio for identifying the most influential customers, based on the criteria of social influence and customer satisfaction. In a survey, we present empirical evidence of customer referral value being a crucial factor for boosting an enterprise's profitability.

Keywords: Customer Referral Value, Customer Life Time Value, Customer Segmentation, Social Influence, Social Networks.

\section{Introduction}

With today's flood of advertising on all conceivable media, people are overloaded with product information. Considering the variety of offers, it is difficult to get an overview and it is extremely time-consuming to find an appropriate product. In this media-dominated world, we tend to go back to the simplest form of obtaining trusted information by asking friends for recommendations and advice. Word-of-mouth communication is obviously more persuasive than company-initiated campaigns (Brown and Reinigen 1987). In spite of this, the referral value of a customer has largely been neglected even though in many industries customer recommendations are the most important source of acquiring new customers. This can often be attributed to the difficulty of measuring social influence.

The evolution of Web 2.0 has changed the behavior of companies regarding online channels and, in its wake, the means of communication between customers and suppliers have changed enormously.

Nowadays, customers obtain all their product information and recommendations online or via social networks, rarely going to brick-andmortar businesses for those purposes. Doing so could be considered a waste of time, as time is becoming increasingly valuable.

Communication among customers about products and services has become easier than ever. Friends, colleagues, relatives and club members speak about

\footnotetext{
* Professor, HWZ University of Applied Sciences in Business Administration Zurich, Switzerland.
} 
their experiences with products and services and express their opinions all the time. It is believed that a customer's social network has more influence on the buying decision than any other source. Customers place more trust in the opinions of people they know than in people they do not know, such as a sales clerk in a shop or a stranger on the internet. Survey results report the impact of word-of-mouth referrals in various contexts: a survey in Sweden and the US indicates that those who transmitted word-of-mouth advertising told on average 9.49 and 7.88 other persons, respectively (Lee et al. 2006).

There is evidence suggesting that the social network of a customer has more influence on the acquisition of new customers than any other source. Satisfied customers generate new clients through positive word-of-mouth advertising.

Research has shown that customers, who have been acquired through referrals, are more profitable (Villanueva et al. 2008). Positive referrals reduce the acquisition costs of a company. Conversely, dissatisfied customers with high influence could generate a market loss.

A survey based on customers who have interacted with the customer service of a mid-sized company shows that negative experience with products or services spreads much faster than positive experience (Dimensional Research 2013). A rule of thumb says that people share their negative experiences with twelve people and positive experiences with three people (Scharioth 1993). There are other empirical results indicating that the relationship between positive and negative experience is symmetric (Anderson 1994). The results of an exploratory study indicated that word-of-mouth, both positive and negative, is a relevant factor that can influence the attitudes and buying behavior of customers (Charlett et al. 1995).

In any case, we have to consider negative experience as a crucial factor when measuring customer referral value. It is no longer sufficient to measure the customer's monetary lifetime value. Instead, consideration must also be given to the customer's social influence. This can provide increased insights into their buying behavior.

Social score providers like Klout, PeerIndex and Kred try to identify opinion leaders with high social influence in social media. Can we use them to measure the influence on our customers? How can we use the sphere of influence of a customer within their network to increase purchases?

\section{Methodology}

We will first discuss ways of identifying customer influence, and then propose a model to measure the customer referral value (CVR) considering positive and negative word-of-mouth. However, we will not test the proposed enhanced CVR model in this study. In a first step, we need to examine the relevant parameters. In a survey, we will try to answer following questions, which are relevant to judge the implementation feasibility of the proposed model: 
Q1: Does word-of-mouth have an effect on the attitudes and probability of purchase of potential consumers in the Swiss market?

Q2: Do negative word-of-mouth referrals have a stronger effect than positive ones on consumers' probability of purchase?

Q3: Are Swiss consumers willing to provide information to companies in order to measure their social influence?

\section{Identifying Customer Influence}

In a first phase, a Social Scoring Service like Klout collects data from social networking sites, blogs, forums, Q\&A sites and other online activities from the social web. In the next phase, profiles, followers, interactions and various contributions are valued. Each scoring service uses its own assessment method. Then, the scores are calculated and displayed. However, in order to calculate the score, the users should allow access to their data (Schaefer 2012).

In addition to the full score values, certain parts are specified: Customer's True Reach is the number of people who are influenced. Klout tries to filter out spam and bots and focus on the people who act on content. Amplification shows the intensity of influence on other people. When a customer posts a message, for example, we want to know how many people respond to it or spread it further. Network Impact quantifies the effect of the potential opinionmaker on other opinions.

These scores can provide valuable data for the detection of the recommendation value of the customer. However, one should understand the limitations of these services. When looking at different countries, for example, you will realise that the comparison of the ratings does not make any sense. People in German-speaking countries are particularly active on Xing. Xing is not taken into account by most services for the calculation of the social scores. In China, local social networks in particular are used as the government blocks the Western social networks. In addition, persons who do not provide their data for the evaluation of social scores will get a lower score.

The influence of the customer can be quantified alternatively by using the information provided by account managers. Information such as image of the customer, his awareness among the public, his affiliation with interesting target groups and the number of customers that he has contacted via word-of-mouth advertising can be used for the evaluation.

Another way of collecting customers' willingness to give referrals is using surveys. Based on that information, customers can be clustered in "active positive ambassadors", "neutral ambassadors" and "active negative ambassadors". By using internal data, the influence of customers can be estimated more precisely. In one project at a telecommunications company, we identified, for example, the opinion leaders by evaluating the number of incoming and outgoing calls (Xevelonakis and Som 2012).

Merging Sentiment Analysis and Network Analysis delivers another method of identifying influencers and their attitudes. A social network in our 
context is comprised of potential or existing customers connected by friendship, kinship, common interest, beliefs and financial exchange. A diagram is used to display these relationships, where customers are the nodes and connections are the lines (Sharma 2012). Using tools like NodeXL, social networks can be visualized. Sentiment analysis uses text mining on social media data to translate written text in a positive, negative or neutral expression (Killian et al. 2013). Text Mining uses techniques from information retrieval, information extraction as well as natural language processing (NLP) (Hotho et al. 2005). Combining both techniques, we can get all the information we need to identify customers who are most likely to have a high impact on other customers and whether they have a positive, negative or neutral attitude to the company (Figure 1).

\section{Figure 1. Leader-Attitude-Portfolio}

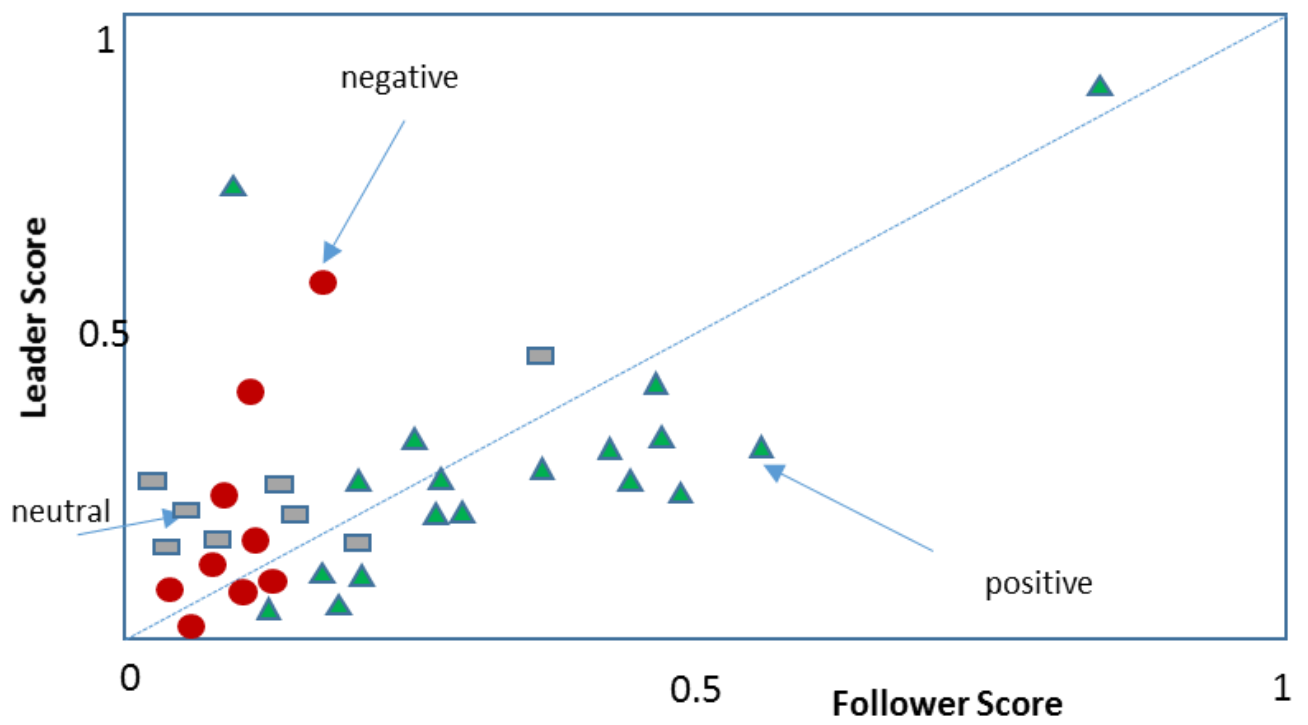

In order to identify the leaders and followers we can use the authority and hub weight. A high hub weight is assigned to customers who frequently react to articles posted by others. A high authority weight is assigned to customers whose articles generate a lot of comment.

\section{Calculating the Customer Referral Value}

Research has shown that customers with a high Customer Lifetime Value are not necessarily the same customers as those with a high Customer Referral Value. Therefore, in order to manage the customer efficiently both measures are required (Kumar et al. 2010).

An interesting approach, developed by Strauss and Seidel in 2002 and expanded by Helm in 2004 (Helm 2004), has attempted to evaluate the beneficial and harmful effects of customer recommendations, respectively. However, this approach is based on a simple calculation of averages for the 
entire customer base. These considerations are adapted below in an attempt to expand the model with individual customer recommendation values.

To illustrate the model, a fictitious example of two clients of a company is used. The first customer is delighted with the performance of a product purchased and the second one disappointed. The aim is to calculate the recommendation value of both customers. In Table 1, the data listed is used for the calculation (Xevelonakis 2013).

The satisfaction level of customers can be obtained from surveys. In addition, relevant conclusions related to the recommendation can be drawn from an analysis of complaints. The size of a customer's social network $\left(\mathrm{SN}_{\mathrm{t}}\right)$ can be determined using the indicator "True Reach", which is offered for example by social scoring service Klout. This size can be specified in more detail with the aid of internal data. The recommendation rate and dissuasion rate, respectively, $\left(\mathrm{u}_{\mathrm{t}}\right)$, can be determined using the indicator "amplification". A negative recommendation rate indicates that the customer advises against the purchase. The higher the amplification value, the greater the influence of customers on his network. Thus, the number of customers $\left(a_{t}\right)$ who can be acquired by customer $(\mathrm{k})$ within a period of time $(\mathrm{t})$, can be estimated as follows:

$$
\mathrm{a}_{\mathrm{t}}=\mathrm{SN}_{\mathrm{t}} * \mathrm{y}_{\mathrm{t}} * \mathrm{u}_{\mathrm{t}}
$$

The referral value RV of the customer (k) is therefore obtained by multiplying the number of acquired customers with their payment surplus $\left(\mathrm{R}_{\mathrm{t}}-\mathrm{C}_{\mathrm{t}}\right)$

$$
R V(k)=\sum_{\mathrm{t}=0}^{n} \frac{\left(R_{r}-c_{c}\right)^{*} \underline{G}_{r}}{\left[(1+i)^{r}\right.}
$$

\begin{tabular}{|c|c|c|c|}
\hline & \multicolumn{2}{|c|}{ Customers } & Potential Sources \\
\hline & Customer A & Customer B & Customer database \\
\hline Revenue $\left(\mathbf{R}_{t}\right)$ per year & 1000 & 1000 & $\begin{array}{c}\text { Billing database, } \\
\text { Predictive modelling }\end{array}$ \\
\hline Costs $\left(C_{t}\right)$ per year & 200 & 200 & $\begin{array}{c}\text { Controlling, } \\
\text { Predictive Modelling }\end{array}$ \\
\hline Satisfaction & enthusiastic & disappointed & $\begin{array}{l}\text { Satisfaction survey, } \\
\text { Sentiment analysis }\end{array}$ \\
\hline $\begin{array}{l}\text { Network Size (Number of } \\
\text { Persons) }\left(\mathrm{SN}_{\mathrm{t}}\right)\end{array}$ & 100 & 100 & $\begin{array}{l}\text { Social network } \\
\text { analysis }\end{array}$ \\
\hline $\begin{array}{l}\text { Ratio of the customers in the } \\
\text { social network who will be } \\
\text { informed about the customer's } \\
\text { experience }\left(y_{t}\right)\end{array}$ & $5 \%$ & $15 \%$ & $\begin{array}{l}\text { Social network } \\
\text { analysis }\end{array}$ \\
\hline Time period (n) & 6 & 6 & \\
\hline Interest rate (i) & $3 \%$ & $3 \%$ & Controlling \\
\hline Referral conversion rate $\left(u_{t}\right)$ & $60 \%$ & $-80 \%$ & $\begin{array}{c}\text { Social scorings, } \\
\text { Sentiment analysis }\end{array}$ \\
\hline
\end{tabular}

Table 1. Parameters for Calculating a Customer's Referral Value (Example)

Source: Author's estimations. 
Based on the data in the above table and the formulas (1) and (2) we can calculate the referral value of customer A in euros, produced by positive wordof-mouth advertising:

Potential customers: $\mathrm{a}_{\mathrm{t}}=\mathrm{SN}_{\mathrm{t}} * \mathrm{y}_{\mathrm{t}} * \mathrm{u}_{\mathrm{t}}=100 * 5 \% * 60 \%=3$ new customers

Therefore, the RV of customer A is calculated as followed:

$$
R V(A)=\sum_{t=0}^{6} \frac{(1000-200) * 3}{(1+0,03)^{t}}=13^{r} 391,3 .
$$

In the same way, we can calculate the referral value for the customer B, initiated by negative word-of mouth-advertising:

$$
R V(B)=-53^{t} 565.2 .
$$

\section{Segmenting Customers Based on Customer Influence}

As part of comprehensive referral management, a company has to identify the influence and the satisfaction level of each customer in order to apply the methods discussed. Using these dimensions a customer portfolio can be derived, which classifies customers in different segments (Figure 2).

Figure 2. Customer Influence Satisfaction Portfolio

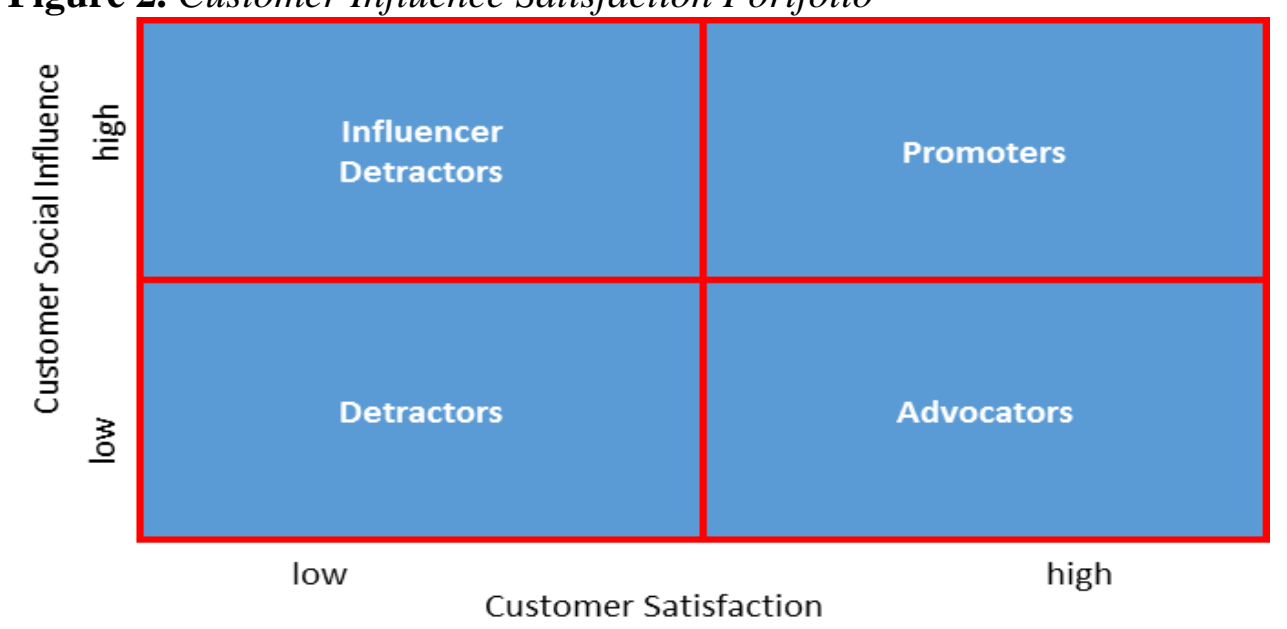

Source: Author's estimations.

The Influencer Detractor (in our example customer B is disappointed with the seller and has a high social impact. He can generate a high market loss due to negative publicity. A general observation is that communication is asymmetrical among people. Negative experiences spread incomparably wider and faster than positive ones. The intensity of the spread certainly depends on the social impact of the person and the degree of dissatisfaction. 
The Promoter (in our example customer A) has a high social impact and is thrilled with the performance of the company. He can acquire new customers by his positive word-of-mouth referrals.

The Detractor and the Advocator have, in comparison, lower impact on the referral strategy of the company.

In conclusion, using social scores, internal data and knowledge a company can estimate the referral value of a customer including it in the development of its marketing strategy.

\section{Empirical Results}

In a quantitative survey ${ }^{1}$ we have tried to evaluate the practical relevance of the methods of identifying customer influence. Over 100 persons participated in this survey in the German part of Switzerland. The results show that word-of-mouth advertising is the most important source in customer acquisition. $84 \%$ of all participants trust the opinions and experiences of friends, colleagues, relatives and club mates the most. A very interesting result was that only $24 \%$ of all participants trust in the opinions of sales clerks in shops. $79 \%$ of all participants would buy a product because it was recommended by friends, colleagues, relatives, club mates and so on. We did not expect this value to be so high. Additionally, $94 \%$ of all participants share their opinions of and experiences with products and services with their friends, colleagues, relatives, club mates and so on. Astoundingly, of those $94 \%$ almost all share their opinions of and experiences with products and services orally within their social network.

Another very important result is that negative word-of-mouth advertising spreads much faster than positive, but not as much as assumed and not at a ratio of $3: 12$. The results of the survey indicate that people share their negative experiences $20-25 \%$ more than positive experiences. Strictly speaking, the results showed a ratio of 5:6. This means that positive experiences with a product or a service are passed on to five people and negative experiences to six. This result is very significant because it shows that a company must also react to negative publicity.

The last question that we tried to answer was whether or not carrying out a survey is an appropriate way to measure influence. $60 \%$ of all participants would give the company their personal data about their social network activities. Nevertheless, to increase responsiveness an incentive should be offered. The survey showed that rebates, better service or gifts are the best way to convince customers to participate in the survey. At the beginning, we thought we could use the information about social networks over Social Scoring Services like Klout, Kred and PeerIndex. Unfortunately, the survey showed that almost no one in Switzerland uses these services.

\footnotetext{
${ }^{1}$ Christian Schnopp carried out an empirical study as part of his Bachelor Thesis at the HWZ University of Applied Science in Business Administration Zurich in January 2015.
} 


\section{Conclusions}

The results of this empirical study indicate that word-of-mouth is a powerful factor, which influences the purchasing behavior of customers.

As several authors argue, it appears that negative word-of-mouth is more influential than its positive variant. However, these empirical results should be viewed with caution. The sample sizes used in the study are fairly small and therefore not necessarily representative of the population. Nevertheless, in looking at the results, it becomes clear that many companies should rethink their customer strategy and make it easier for their customers to communicate positive referrals of their products and services. Using internal and external data to identify both the social influence and the attitudes of customers is becoming more relevant. Negative word-of-mouth should be taken into consideration as a relevant factor for calculating the real customer referral value. Applying this knowledge, a company will be able to segment its customers and define the right strategy to increase marketing efficiency. However, further research is needed to validate the implementation feasibility of the proposed enhanced CVR model in the campaign management process.

\section{References}

Anderson EW (1994) Post-Purchase Evaluations and Word-of-Mouth. National Quality Research Center - University of Michigan Business School 94(10).

Brown JJ, Reingen PH (1987) Social ties and word-of-mouth referral behavior. Journal of Consumer Research 14(3): 350-362.

Charlett D, Garland R, Marr N (1995) How damaging is negative word of mouth? Marketing Bulletin 6: 42-50.

Dimensional Research (2013) Customer Service and Business Results: A Survey of Customer Service from Mid-Size Companies. Retrieved from https://goo.gl/i92vqc. [Accessed: 22 May 2015]

Helm S (2004) Kaufempfehlungen als Baustein des Kundenwertes [Buy recommendations as a building block of customer value]. Grundlage des CRM S. 321-335.

Hotho A, Nuernberger A, Paass G (2005) A brief survey of text mining. GLDVJournal for Computational Linguistics and Language Technology 19-62.

Killian T et al. (2013) Creating Usable Customer Intelligence from Social Media Data https://goo.gl/MR4sxL [Accessed: 5 May 2015]

Kumar V, Andrew JP, Leone RP (2010) Driving profitability by encouraging customer referrals: who, when, and how. Journal of Marketing 74: 1-17.

Lee J, Lee J, Feick L (2006) Incorporating word-of-mouth effects in estimating customer lifetime value. Database Marketing \& Customer Strategy Management 14(1): 29-39.

Schaefer MW (2012) Return on Influence: The Revolutionary Power of Klout, Social Scoring, and Influence Marketing. New York: McGraw-Hill.

Scharioth J (1993) Wie Sie Kunden durch Kommunikation binden [How to retain customers through communication]. Gablers Magazin 7(1): 22-24.

Sharma N (2012) Sphere of Influence. Retrieved from http://goo.gl/ICKo4Z. [Accessed: 4 April 2015] 
Villanueva J, Yoo S, Hanssens DM (2008) The impact of marketing-induced versus word-of-mouth customer acquisition on customer equity growth. Journal of Marketing Research XLV: 48-59.

Xevelonakis E, Som P (2012) The impact of social network based segmentation on customer loyalty in the telecommunication industry. Journal of Database Marketing \& Customer Strategy Management 19(2): 98-106.

Xevelonakis E (2013) Sozialer Einfluss und Kundenempfehlungswert im Zeitalter der Social Media [Social influence and customer referral value in the Age of Social Media]. Interview Magazin 6: 42-44. 
